\title{
LA EDUCACIÓN DE LA MIRADA ESCRUTADORA EN JORGE OTEIZA: "NATURALEZA, ARTE Y ESPIRITUALIDAD"
}

\author{
FERNANDO ECHARRI IRIBARREN ${ }^{1}$ \\ Universidad de Navarra \\ Emilio Varela Froján ${ }^{2}$ \\ Universidad del País Vasco
}

\begin{abstract}
La realidad que nos muestra la naturaleza posee múltiples mensajes. Estos mensajes se comunican continuamente con el individuo estableciéndose un vínculo persona-naturaleza. Este vínculo puede ser representado y estudiado mediante el hecho artístico o creativo. El presente artículo muestra algunas de las múltiples conexiones que se establecen entre la naturaleza y las personas, incorporando una dimensión estética de la realidad y una dimensión metafísica. Como ejemplo sincrético de un proceso naturaleza-realidad, estética-arte y trascendencia-espiritualidad, se destaca el caso del escultor Jorge Oteiza. En concreto se estudia la conceptualización de su obra, de forma sintética, a través de su relación y experiencias significativas de vida (SLE) con la naturaleza, expresada en su pensamiento estético y representada en su obra artística.
\end{abstract}

Palabras clave: Educación estética; arte, naturaleza y espiritualidad; educación ambiental; experiencias significativas de vida (SLE).

\section{THE EDUCATION OF THE PENETRATING GAZE IN JORGE OTEIZA:} "NATURE, ART AND SPIRITUALITY"

Reality shown by nature gives us multiple messages. These messages communicate continuously with each individual thereby establishing a strong person-nature link. This link can be represented and studied via an artistic or creative act. This study shows some of the multiple connections established between nature and people, including the aesthetic and metaphysical dimensions of reality. As a syncretic example of a process nature-reality, aesthetic-art and spirituality-transcendence, the case of the sculptor Jorge Oteiza is outstanding in terms both of his life and work. The author studies the conceptualization of his work, in a synthetic way, through its connection to significant life experiences (SLE) with nature, expressed by his aesthetic thought and represented in his art.

Key words: Aesthetic education; arts, nature and spirituality; environmental education; Significant life experiences (SLE).

Cómo citar este artículo / Citation: Echarri Iribarren, Fernando / Varela Froján, Emilio (2017): "La educación de la mirada escrutadora en Jorge Oteiza: 'Naturaleza, arte y espiritualidad'”. En: Archivo Español de Arte, vol. 90, núm. 360, Madrid, pp. 411-428. doi: 10.3989/aearte.2017.27

\footnotetext{
1 fecharri@unav.es / ORCID iD: http://orcid.org/0000-0003-1886-8927.

2 evarela@coavn.org / ORCID iD: http://orcid.org/0000-0001-8587-7968.
} 


\section{El vínculo persona-naturaleza}

Ana Mari Marín -“Jorge: ¿tú te impones a la naturaleza?”

Jorge Oteiza -"No. Yo me abrazo a ella"

(Conversación entre Ana Mari Marín y Jorge Oteiza ${ }^{3}$ )

La naturaleza puede ser entendida como un concepto amplio que abarca la realidad tangible que nos rodea, nos constituye y con la que convivimos. Esta realidad natural proporciona constantes mensajes a las personas ${ }^{4}$ que en muchos casos obtienen respuesta por parte de los individuos, generando diferentes percepciones personales sobre el medio natural ${ }^{5}$. Por ejemplo, ante el inevitable mensaje relacional que la atmósfera nos proporciona, se sucede la comunicación con ella, a través de la respiración continua. O ante el mensaje de las frutas, resulta la ingestión del alimento natural. A estas comunicaciones que se establecen frente a necesidades tan primarias, pueden añadirse otro tipo de mensajes, muchos de ellos silenciosos o secretos, que se producen mediante la naturaleza ${ }^{6}$, y que pueden trascender la propia materia, llegando a lo intangible. Todo este conjunto de comunicaciones de la relación persona-naturaleza establece y conforma un vínculo $^{7}$. Este vínculo humano-natural genera y construye parte de nuestra identidad ${ }^{8}$ y puede ser entendido de formas muy diversas. Por un lado puede ser entendido como un vínculo de complementariedad, un vínculo de necesidad mutua que va incluso más allá de la pura necesidad e interdependencia física, para superarlo y crecer hacia una interdependencia metafísica que puede dar lugar a comportamientos proambientales ${ }^{9}$, En otras ocasiones el vínculo es reducido sólo a un componente exclusivamente materialista que, con una visión utilitarista, conlleva comportamientos de explotación total de los recursos ambientales ${ }^{10}$. Esta visión reduccionista considera al universo como una colección de objetos más que como una comunión material ${ }^{11}$, una "mercancía que nos pertenece"12. Las consecuencias de esta visión no son inocuas, sino que producen graves problemas ambientales ${ }^{13}$. Por eso es necesario desarrollar una conciencia más profunda de nuestra interdependencia con la naturaleza ${ }^{14}$ y restituir una deteriorada harmonía entre lo humano y lo ambiental ${ }^{15}$.

\section{Naturaleza y espiritualidad: Experiencias Significativas de Vida}

Nuestro vínculo con la naturaleza, que afecta directamente a la forma en la que nos relacionamos con ella, está condicionado por la capacidad que tenemos de observarla, de contemplarla, de descubrirla, de interpretarla. En estas habilidades cognitivas intervienen tanto la inteligencia

\footnotetext{
${ }^{3}$ Cita obtenida de la entrevista realizada por Fernando Echarri a Ana Mari Marín el 9 de abril de 2015. La respuesta de Oteiza muestra, en cierto modo, su visión acerca del vínculo persona-naturaleza. Un vínculo no utilitarista, afectivo, espiritual, que Oteiza explora, trata de comprender, desentrañar, reforzar y buscar su significado.

${ }^{4}$ Clayton/Myers, 2015.

5 Tsevreni, 2011.

6 "Things 'catch our eye' and sometimes refuse to let go: they 'grab our focus' and 'capture our attention', and finally release us from their grasp only to dissolve back into the overabundant world". Abram, 2010: 50.

7 Abram, 1996; 2010. Barnhardt/Kawagley, 2010. Clayton/Myers, 2015.

8 Clayton/Myers, 2015: 168.

9 Según el modelo propuesto por Kollmuss/Agyeman (2002) y la ética de la tierra propuesta por Leopold: "Cuando veamos la tierra como una comunidad a la que pertenecemos, tal vez empecemos a usarla con amor y respeto" (Leopold, 1966: Foreword [X]).

10 Thoreau, 2004: 175.

11 Flowers/Lipsett/Barrett, 2014. Berry, 1988: 107.

12 Leopold, 1966: Foreword [X].

13 Declaration of the United Nations Conference on the Human Environment, 1972. Bai, 2009. Plumwood, 2002.

${ }^{14}$ Russell, 2012.

15 Clayton/Myers, 2015: 241.
} 
natural como la inteligencia trascendente ${ }^{16}$, llamada también espiritual ${ }^{17}$. La primera actúa más en el plano físico, desvelando "las reglas, el modo de ser y de funcionar de lo natural que la ciencia experimental va descubriendo"18; la segunda se centra más en lo intangible, en la espiritualidad, que emana de la material natural, en lo que podríamos denominar también como inteligencia espiritual ecológica ${ }^{19}$. Este tipo de inteligencia busca la percepción y desarrollo del componente espiritual al que la materia apunta ${ }^{20}$. La inteligencia espiritual ecológica nos ayuda a completar el vínculo persona-naturaleza, de un "modo libre y también profundo" 21 . La inteligencia espiritual ecológica busca una comprensión de nuestro mundo que responda las preguntas sobre su sentido, en ocasiones trascendentes, que afloran a través de un contacto con él, o de su estudio y contemplación. Facilita, en definitiva, una comprensión profunda del vínculo que establecemos con la naturaleza.

Entre las posibles vías que existen para comprender, descubrir, conformar, conocer o reconocer el vínculo persona-naturaleza se encuentran las llamadas experiencias significativas de vida ${ }^{22}$ (en adelante SLE). Quienes las experimentan pueden desarrollar profundos intereses, preocupaciones y acciones proambientales a lo largo de toda su vida ${ }^{23}$. Las SLE interesan por la duración del aprendizaje que comporta, la globalidad de su alcance, y por la magnitud de las decisiones y consecuencias ambientales que de ellas se derivan. En definitiva, pueden dirigir a las personas hacia compromisos ambientales exigentes y a largo plazo. Su conocimiento y promoción se constituye como uno de los retos de la educación ambiental del siglo $\mathrm{XXI}^{24}$.

De entre las tipologías de SLE se podría destacar las que afectan a una dimensión espiritual de la persona. Se trata de las llamadas environmental epyphanies ${ }^{25}$, consideradas como experiencias trascendentes ${ }^{26}$. Este tipo de experiencias producen en las personas una respuesta de un gran nivel de intensidad, acaso un estado emocional y espiritua ${ }^{27}$ de una potencia inusitada, raramente experimentada y por ello largamente recordada, quizá inolvidable ${ }^{28}$. Estas experiencias quedan grabadas a fuego en el corazón para toda la vida.

Cabe decir que las environmental epyphanies son "acontecimientos comunes" 29 . No en el sentido de que sean cotidianas en la vida de una persona, sino en el de que muchas personas las reconocen en algún momento de sus vidas. Vining/Merrick o Hedlund-de Witt ${ }^{30}$ proponen profundizar en su estudio, conocedores de las enormes posibilidades que presentan para potenciar la comprensión del vínculo persona-naturaleza. Pero raramente son estudiadas y mencionadas en la bibliografía ${ }^{31}$, tal vez por adentrarse en ámbitos "emocionales" 32 o "espirituales"33 difíciles de racionalizar. Estas experiencias generalmente refuerzan la conciencia del vínculo con lo natural: "Todos los objetos del universo convergen y manan hacia mí perennemente. Todos me traen un mensaje, y debo descifrarlo" 34 .

\footnotetext{
16 Gardner, 2010.

17 Wolman, 2001. Mallarach, 2008. Torralba, 2011. Castro, 2012.

18 Puig/Echarri/Casas, 2014.

19 Francisco I, 2015.

20 Puig/Echarri/Casas, 2014.

$21 \mathrm{Puig} /$ Echarri/Casas, 2014.

22 Tanner, 1980. Chawla, 1998; 1999; 2001.

23 Chawla, 1998.

24 Palmer, 1998.

25 Vining/Merrick, 2012.

26 Williams/Harvey, 2001. Clayton/Myers, 2015: 241.

27 Hawks, 1994.

28 Vining/Merrick, 2012.

29 Vining/Merrick, 2012.

${ }^{30}$ Vining/Merrick, 2012. Hedlund-de Witt, 2013.

31 Hawks, 1994.

32 Kollmuss/Agyeman, 2002.

${ }_{33}$ Keniger/Gaston/Irvine/Fuller, 2013.

34 Whitman, 1981: 136.
} 


\section{Naturaleza y su relación con el arte y la espiritualidad: el caso de Jorge Oteiza}

En la construcción del vínculo de la persona con lo natural se incluye también la expresión estética, como forma de representar e interpretar la naturaleza. Y es que cuando aparece la visión estética ligada profundamente a la realidad, aparece también el arte y sus formas, que trastorna el orden aparente del mundo exterior, provocando la necesidad de una más profunda comprensión de uno mismo. Como ejemplo donde se concreta la posibilidad a la que apunta la visión sincrética del trinomio "naturaleza-arte-espiritualidad", de entre los posibles ${ }^{35}$, se expone el caso representativo del escultor Jorge Oteiza. En el artista oriotarra convergen la mirada plena y consciente a la naturaleza - una mirada escrutadora, necesitada de desentrañar el significado profundo de lo que son las cosas-, el vínculo que establece con ella su conciencia mediante su inteligencia espiritual, y sus expresiones estéticas y poéticas a través de sus representaciones y formas artísticas.

Tanto la obra plástica como teórica de Jorge Oteiza, tanto su estética como su poética, se nutren no sólo de la historia de las artes, que el artista conocía en profundidad ${ }^{36}$, sino también, y de forma más importante, de la relación directa que desde niño estableció con la naturaleza. La importancia de la naturaleza en la conceptualización de su obra es manifiesta ${ }^{37}$. Y este protagonismo que la naturaleza adquiere en su obra, posiblemente es fruto de un fuerte vínculo significativo $^{38}$ que Oteiza estableció con ella ya desde niño.

Son numerosos los ejemplos de encuentros significativos de Oteiza con la naturaleza. La significatividad de esos primeros encuentros desarrolló bien pronto en el artista una gran sensibilidad espacial para reconocer en ella su propio estado interior. De esta forma ayudaron a conformar una educación estética de la sensibilidad que luego, de una forma consciente, aplicaría a su obra y pensamiento. Su biografía está llena de múltiples experiencias iniciáticas. Se trata de episodios como el de la playa, la cantera, la ría o el mirador ${ }^{39}$, que más tarde, ya como escultor, reconocería como claves en su trayectoria de artista ${ }^{40}$.

Oteiza establece un vínculo donde identifica los espacios de la naturaleza con los espacios interiores o, lo que es igual, la realidad física exterior con los espacios íntimos de su conciencia. Oteiza consigue así transformar la naturaleza y realidad espaciales en unas estéticas y unas poéticas de lo existencial. Así fabrica, no objetos artísticos, sino unas protecciones espirituales para la sensibilidad y, por consiguiente, crea una nueva metafísica para el comportamiento humano con lo natural. Estas estéticas y poéticas incluyen lo visual, no como belleza ${ }^{41}$, imagen e imitación de la naturaleza o Naturalismo ${ }^{42}$, sino como inmovilidad -visión distinta al paisaje y a la máscara-, que es la forma visible del silencio o el límite de la visión, vacío y transparencia, en el espacio y la luz de la conciencia.

Porque existen realidades en la naturaleza que no se pueden conocer a través de la ciencia y su método científico, sino únicamente a través de la conciencia ${ }^{43}$. Es decir, que se conocen no en el experimento sino en la experiencia. Son estas realidades las que finalmente pueden quedar registradas en las obras de arte, como si fueran también formulaciones y ensayos sobre la naturaleza, pero en las dimensiones estéticas y poéticas de la realidad. Porque la naturaleza, que in-

5 Por ejemplo: Whitman, 1981, Ernest-Thompson Seton, 1941 o César Manrique, 2005.

36 Oteiza, 1997.

37 Oteiza, 2007a: Naturaleza y Arte.

38 "Emotional involvement" (Kollmuss/Agyeman, 2002).

39 Pelay Orozco, 1978: 64.

40 Pelay Orozco, 1978: 63.

41 Oteiza, 2007b: 135-136.

42 Oteiza, 2007b: 137.

${ }^{43}$ Mientras que para conocer la vida y su naturaleza se emplean las ciencias, el conocimiento de su realidad sólo es posible a través de la conciencias. Para la realidad metafísica se podría decir que requiere, más que de mucha imaginación, de mucha conciencia. Y esto consistiría, concretamente, en un pensamiento preparado no para imaginar sino para darse cuenta. 
cluye mensajes tanto físicos como metafísicos, va a ser desentrañada por la escrutadora mirada del artista quien, con absoluta clarividencia ${ }^{44}$, los conecta con su inteligencia y sensibilidad:

Todo es ya sensible desde lo estético. Cuando el arte experimentalmente concluye, todo el arte pasa a ser Naturaleza. Ya toda la Naturaleza (y todas las naturalezas) tienen explicación natural y estética. Esta es una de las más fundamentales conclusiones del arte contemporáneo que todos debieran haber comprendido ${ }^{45}$.

\section{Conciencia metafísica y "educación estética de la sensibilidad"}

En la evolución del pensamiento de Oteiza, su actitud cambia: pasa de apropiarse de todo lo que hay en la naturaleza a acercarse realmente a ella en un proceso sensible de aproximación, identificando el espacio natural al espacio de su conciencia; y a no suponer en ella contenidos que sólo a él pertenecen y a los que la naturaleza es ajena. De esta forma, atraviesa su propia subjetividad que hace objetos a todas las cosas y trasciende su materia. Y siente lo sobrenatural no como la imaginación de la naturaleza sino como conciencia metafísica, que el artista identifica con algunos espacios naturales. En este sentido, se podría hablar de "reservas espirituales" 46 en la naturaleza, que tienen el mismo tamaño y la misma función que la conciencia.

Siendo el arte lo que modifica su comportamiento, lo que hace intervenir a su conciencia, el artista siente que su propia realidad pertenece a la naturaleza y que lo que ella contiene es reflejo de su interior. Y así sus obras, que dejan de ser representaciones para extraer y abstraer imágenes y significados, se convierten en parte de la realidad estética de la naturaleza. Así repite, como al principio, su inmovilidad y su silencio. Es en el contenido de sus límites y de sus vacíos donde el artista reconoce unos lugares afines a su conciencia y, a través de ella, le permite acceder directamente a sus secretos y misterios.

Porque en Oteiza el arte consiste, más que en la fabricación de objetos artísticos, en la "educación estética de la sensibilidad" 47 . Pero, en su caso, lo sensible se encuentra en lo espacial, más allá de la materia y de la forma, concretamente, en las propiedades metafísicas de lo espacial. El artista lo planteó en una "Biología del espacio"48, para la cual inventó y definió, entre otros, conceptos como la "expansión y flotación espaciales", la "rotación espacial", la "suspensión vacía", la "respiración espacial", el "vacío respirando" y la "desocupación activa del espacio"49. Estos conceptos propiciaron la revelación de nuevas realidades espaciales (figs. 1 y 2) y, lo más importante, de nuevos comportamientos a tener en cuenta para una metafísica de la conducta. Esta nueva metafísica incorpora, además de unos nuevos valores estéticos, la necesaria conciencia ambiental. Dice el artista:

Una exposición de obras de arte, es como el laboratorio de un oculista espiritual, que nos mide y gradúa nuestra visión interior. Donde podemos comprobar hasta qué límite o profundidad se nos revela la realidad como revelación espiritual, tanto en el arte como en la naturaleza. Suele decirse que la Naturaleza imita al arte y es por esto: Porque cuando nos sorprendemos felizmente a

44 "Yo no busco ni tengo interés en estar de acuerdo, repito, con la ciencia. Es más, debo reencantar todo lo que ella desencanta: debo, como plástico, vigilar todo lo que ella descuida" (Oteiza, 2007b: 123).

45 Oteiza, 1983: 172: Todo es arte.

46 Oteiza, 1983: 151.

47 Oteiza, 1983: 151

48 Oteiza, 2007a: La Función es antes que la Forma. Aunque su interés primero fue formarse como arquitecto, finalmente, por razones burocráticas, se matriculó en medicina durante tres años en Madrid. Fue gracias a la asignatura de Bioquímica que se despertó en él una vocación experimental por la escultura. Muchos de sus razonamientos posteriores sobre la naturaleza estética del arte vienen de aquellas ideas primeras, que de forma general, el artista concretó en una "biología del espacio".

49 Oteiza, 2007a. 


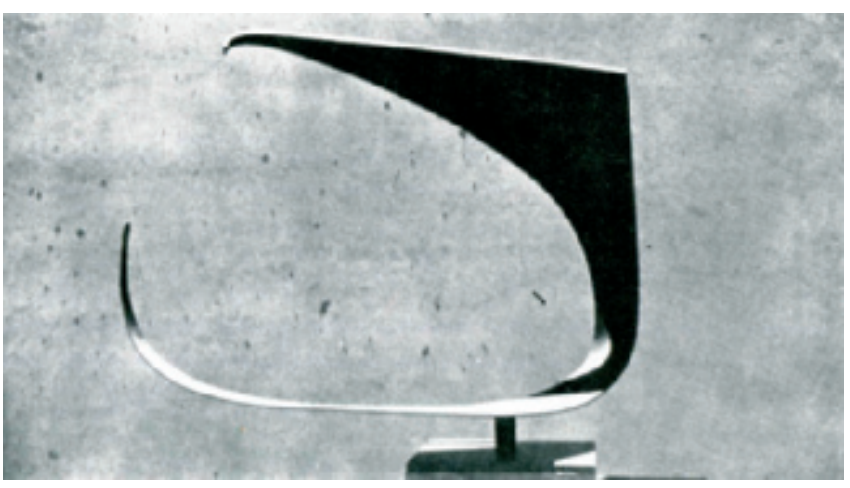

Fig. 1: Suspensión vacía. Homenaje al ingeniero aeronáutico René Couzinet (versión A), 1957. Hierro, $50 \times 43 \times 63 \mathrm{~cm}$. Fuente: Colección del artista. Oteiza, 2007a: Cat. 21.

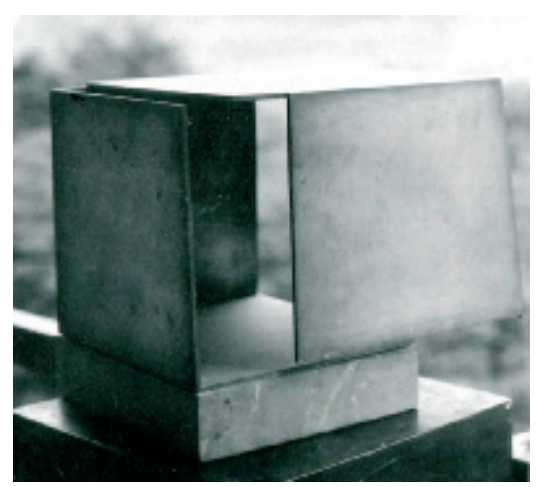

Fig. 2: Vacios respirando, 1958-59. Hierro, $28,5 \times 34,5 \times 24,5 \mathrm{~cm}$.

Fuente: Colección del artista. Badiola, 1998: 211.

nosotros mismos comparando lo que vemos en la naturaleza con lo que hemos visto en el arte, es que estamos recordando y agradeciendo al artista que nos enseñó a ver de ese modo, esa porción de la realidad ${ }^{50}$

Es esta vía de conciencia ambiental la que Oteiza utiliza a través de la educación de su mirada que es capaz de llegar a través de lo matérico a lo espiritual. En cierta forma, a través de la materia y con ella misma, y también a través de su estética, la trasciende para encontrar un nuevo plano de percepción y conocimiento.

\section{La mirada escrutadora en Oteiza y "ley de los cambios en la expresión artística"}

Desde las primeras esculturas (fig. 3), incluida la etapa que el escultor llamó "Encontrismo", hasta las últimas, hay en Oteiza una mirada escrutadora ${ }^{51}$ constante a la naturaleza, que consiste primero en el tratamiento plástico de sus formas y, finalmente, en un tratamiento estético y metafísico de sus espacios. En ambos casos el artista, siempre con intervenciones mínimas, consigue, incluso en sus obras más abstractas, que no sean sólo objetos artísticos, sino que formen parte de la vida y transformen su visión. Decía Oteiza en el mismo lugar de la "Carta a los artistas de América" 52: "La comprensión de esta 'plásticoactividad' natural, que se da con una presencia constante en nuestra vida que nos rodea, convierte la visión habitual del hombre en una forma superior de vida".

De esta manera el vínculo que se establece con la naturaleza no es completo si no se atiende a la dimensión de lo sensible, si se prescinde de la mirada estética y poética de lo natural. "Hay que enseñar a ver", solía insistir César Manrique, apelando a la carga transformadora del ojo, educadora de la mirada ${ }^{53}$. Es precisamente a través del arte como la vida se transforma en todos los sentidos. Realmente este vínculo en Oteiza se materializó en un proceso lento de interiorización, no sólo de su arte en la naturaleza o viceversa, sino de su propia vida en lo más íntimo de la conciencia. Al mismo tiempo que sus esculturas perdían forma y materia para liberar su ener-

\footnotetext{
50 Oteiza, 1983: 81.

51 Oteiza mismo la llama “contemplación” (Oteiza, 1983: 76).

52 Oteiza, 2007b: 290.

53 Gómez Aguilera, 1994: 58-63
} 
gía espacial y activar su dimensión metafísica en el vacío, las ideas simbólicas sobre la naturaleza se iban transformando en pensamientos, no de la imaginación, sino de la conciencia.

Porque el objetivo final del artista no era otro que acceder al interior de su propia naturaleza. La escultura primero, luego la poesía, fueron las herramientas que le permitieron conocer mejor la vida y su sentido: "La realidad del arte se identifica con la realidad de la Naturaleza"54. Fue en la intimidad de la materia y de la palabra donde Oteiza se acercó realmente a la naturaleza, donde fue capaz de sentir su latido y, finalmente, identificarse con ella en sus espacios naturales. Es ahí donde pudo reconocer en ellos lo que le había enseñado la palabra con su silencio y la estatua $^{55}$ en su interior vacío: un espacio puramente receptivo. Son lugares de naturaleza estética y metafísica que

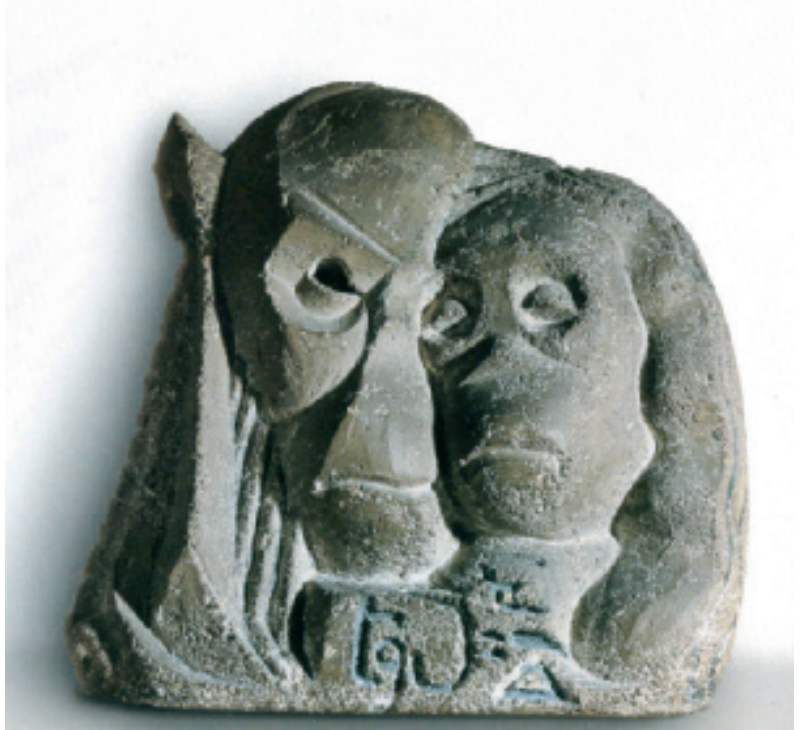

Fig. 3: Adán y Eva. Tangente $S=E / A, 1931$. Cemento, $42 \times 47 \times 15 \mathrm{~cm}$. Colección particular. Fuente: Badiola, 2004: 108. el escultor consigue aislar y dejar disponibles para su conciencia. Lo que supuso para él, en definitiva, este encuentro con la naturaleza y esta experiencia de vida, que expresó de esta forma sencilla el propio artista: "La Naturaleza vuelve a mí"56.

Los vacíos que crea el escultor acaban por reconocerse en los espacios naturales, de los que nacieron y a los que pertenecen. El artista nos enseña así a identificar estéticamente y, más tarde, a comprender en su función metafísica, que no es otra que la de servir como protección a la conciencia. Es esta función metafísica la que mediante una educación estética de la sensibilidad somos capaces de aprender.

Es, por tanto, en esta relación "naturaleza-arte-espiritualidad", más allá de lo físico y la materia, que el escultor desarrolla completas sus dimensiones estética y metafísica. Las resuelve mediante un vacío activo, pero liberado de formas, que convierte en pura receptividad, y que, finalmente, acabará depositando en él su propia conciencia, en un proceso de integración total y de síntesis plástica. Es en este proceso donde terminarán por identificarse para siempre vida natural con vida estética ${ }^{57}$.

Su mirada podría, salvando las distancias, recordar a lo escrutador del catalejo (fig. 4), siempre observando en profundidad y buscando encontrar los mensajes que los elementos del medio natural podían proveerle. Lo dice el propio artista en "Escultura de catalejo" 58 :

Buscaba mirando por el agujero en la piedra el mismo círculo vacío que veía en el cielo desde el fondo de un gran agujero en la playa de Orio en el que me ocultaba y protegía). Recordan-

54 Oteiza, 1983: 72, 73 у 74.

55 Oteiza, 1983: 35.

56 "Lo que tengo es Naturaleza, lo que me falta no es Naturaleza. Me declaro obrero metafísico, vuelo contra la Naturaleza, la traspaso. He terminado mi escultura experimental cuando he logrado vaciar este hueco en el espacio natural, cuando he desocupado formalmente la estatua convirtiéndola en un mueble metafísico, en un espacio interior receptivo, espiritualmente habitable. La Naturaleza vuelve a mí". Oteiza, 1983: 150.

57 Oteiza, 1990a: 12.

58 Oteiza, 1988: 78-79. 


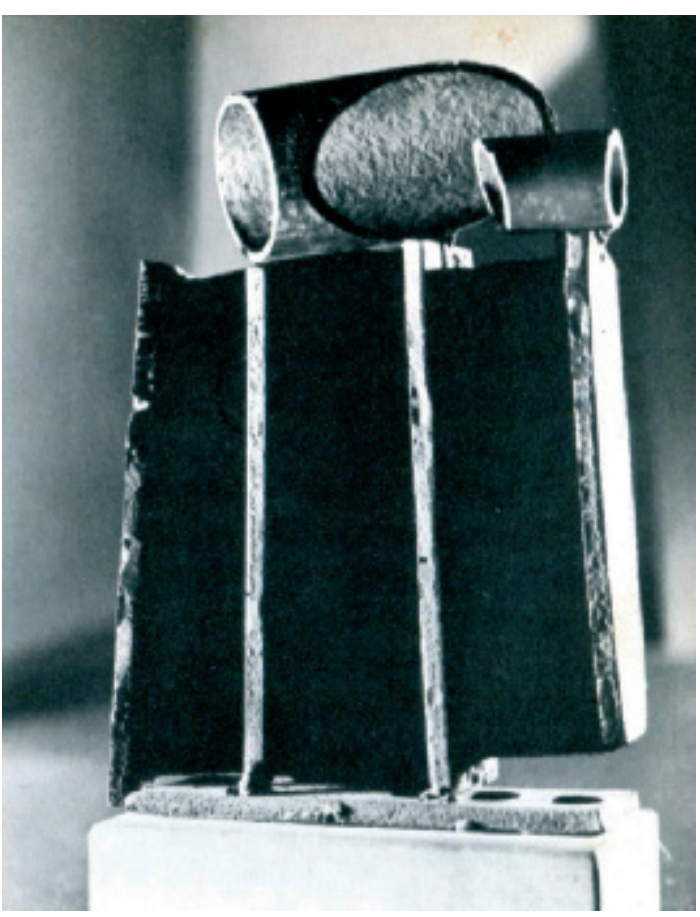

Fig. 4: Buho madre y pequeño buho (recuerdo de mi encontrismo de 1935), 1958. Hierro, $26 \times 8 \times 20 \mathrm{~cm}$. Colección del artista. Fuente: Pelay Orozco, 1978: 309.

do luego esta escultura la he llamado de catalejo. [...] Pues en mi piedra de catalejo se define con el agujero un espacio estéticamente de protección, que en mi conclusión experimental de escultor será el espacio vacío de mis Cajas metafísicas abiertas al mismo tiempo que cerradas y que a través de sus aberturas se vive como un Absoluto, como una nada o vacío de protección.

La conformación y educación de su mirada escrutadora quiere ir más allá del mero plano físico. Al igual que Whitman ${ }^{59}$, Oteiza piensa que es necesario aprender la observación de lo que no se ve. Intuye así que "Todo lo que se ve es sagrado. Y lo que no se ve es una sacralidad oculta, una deficiencia nuestra visual" ${ }^{60}$. Es con la educación de la mirada con la que podemos alcanzar los posibilitadores mensajes que la materia encierra en todas sus dimensiones.

Así, es a partir de la "Ley de los Cambios en el Arte"-herramienta conceptual elaborada por el propio artista para explicar los cambios en la expresión artística ${ }^{61}$, que se pueden establecer, lo mismo para Oteiza y la educación de la mirada, una primera fase en que el escultor considera estéticamente la naturaleza y el cuerpo en su imagen y figura como un paisaje y como una máscara, y una segunda fase donde, después de un proceso de debilitamiento de la forma y silenciamiento de la expresión, Oteiza es capaz de dar con una respuesta estética a la inmovilidad y al vacío en forma de muro y estatua.

El artista que trabajaba en lo simbólico a través de las metáforas, en unas estéticas de la belleza y del ideal, cambia radicalmente, y pasa a trabajar de otra forma distinta, con un material de naturaleza metafísica y en unas estéticas de la inmovilidad y del vacío. Porque, finalmente, el muro y la estatua no son otra cosa que los elementos plásticos y, por lo tanto, la solución estética para la integración, no de la naturaleza en nosotros, como lo son el paisaje y la máscara, sino, contrariamente, de nosotros en la naturaleza, haciendo visibles con nuestras obras su inmovilidad y su silencio.

Si el arte, primero se ocupaba de lo físico, a través de la imaginación del cuerpo, de la naturaleza y de la vida, en construcciones estéticas como las máscaras, los paisajes y los rituales, después, una vez superado lo metafórico y lo simbólico, ya en zona metafísica, cuando trabaja más la conciencia que la imaginación simbólica, el artista precisa de unas nuevas soluciones estéticas, distintas a las anteriores, que estaban referidas especialmente a lo visual. Por tanto las cosas son consideradas como objetos poseedores de una imagen, cuyo ideal no es otro que la belleza.

Oteiza cree que se puede comprender la naturaleza, además de en sus imágenes y en sus paisajes, en la visión de sus vacíos y sus límites. Unas realidades espaciales en que el artista

59 "Mi cuerpo que prescinde de la materia, mi vista que prescinde de los ojos materiales, me han demostrado hoy día, incontestablemente, que no son mis ojos materiales los que ven" (Whitman, 1981: 289).

${ }^{60}$ Merino, 2008: 40.

61 Oteiza, 1990a: 13. 
Fig. 5: Caja Vacía.

Conclusión experimental n. ${ }^{\circ} 1,1958$. Hierro, $30 \times 30 \times 30 \mathrm{~cm}$. Colección privada, Pamplona. Fuente: Pelay Orozco, 1978: 44.

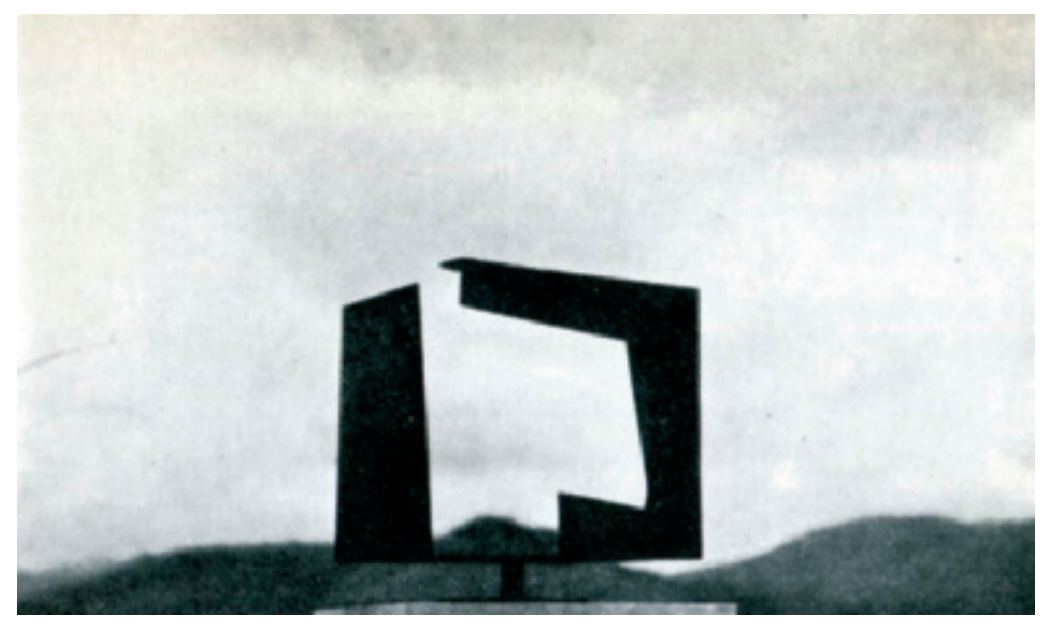

parece reconocer su propia realidad interior y que concreta en unas estéticas donde la visibilidad no es ya la belleza sino lo inmóvil y el vacío.

El artista, en una operación que consiste en liberar los espacios que estaban ocupados, y que deja vacíos, con la intención de disponer nuevamente de ellos, es capaz de activarlos al cargarlos de una nueva energía de naturaleza metafísica y espiritual. Estos espacios vacíos quedan preparados para servir como protecciones estéticas de la sensibilidad, y de trascendencia (fig. 5). Oteiza dice trabajar de manera opuesta en un "estilo defensivo de protección", un "estilo geométrico de inmovilización" 62 , que le permiten otro trato con los espacios de la naturaleza, que, finalmente, identifica con el espacio íntimo de su conciencia.

\section{Algunos ejemplos del vínculo de Jorge Oteiza con la naturaleza: Oteiza y las SLE}

Jorge Oteiza experimentó, ya en su infancia, numerosos episodios que podríamos calificar como SLE que tuvieron un alto poder significativo. Estas experiencias, a través de la naturaleza y que él enmarca en el terreno estético, marcaron al futuro artista. El artista recuerda algunos de estos episodios de la siguiente manera:

\section{Episodio 1. La playa.}

De muy niño, en Orio, donde he nacido, mi abuelo solía llevarnos de paseo a la playa. Yo sentía una enorme atracción por unos grandes hoyos que había en la parte más interior. Solía ocultarme en uno de ellos, acostado, mirando el gran espacio solo del cielo que quedaba sobre mí, mientras desaparecía todo lo que había a mi alrededor. Me sentía profundamente protegido. Pero, ¿de qué quería protegerme? [...] Mi experiencia de niño en ese hoyo en la arena -ustedes

${ }^{62}$ La inmovilidad se define en relación a los silencios; al igual que la imagen cobra sentido con los significados. Es decir, la inmovilidad es la forma visible del silencio. Por lo tanto, la inmovilidad es un momento de la visión, cuando el silencio es en la luz; y también un espacio, en la transparencia y el vacío, donde seguir mirando. Porque existen cosas en la naturaleza que son sin gesto, sin imagen, que no se figuran ni, por tanto, se pueden representar; que mantienen su forma original, antes de que el pensamiento simbólico y el conocimiento abstracto se figurasen imágenes en la inmovilidad y significados en el silencio, antes de que la mirada imaginase paisajes en la naturaleza o máscaras en el cuerpo, y que las ciencias interpretaran la vida con la luz de la imaginación y no con la conciencia que respeta sus límites y sus secretos. 


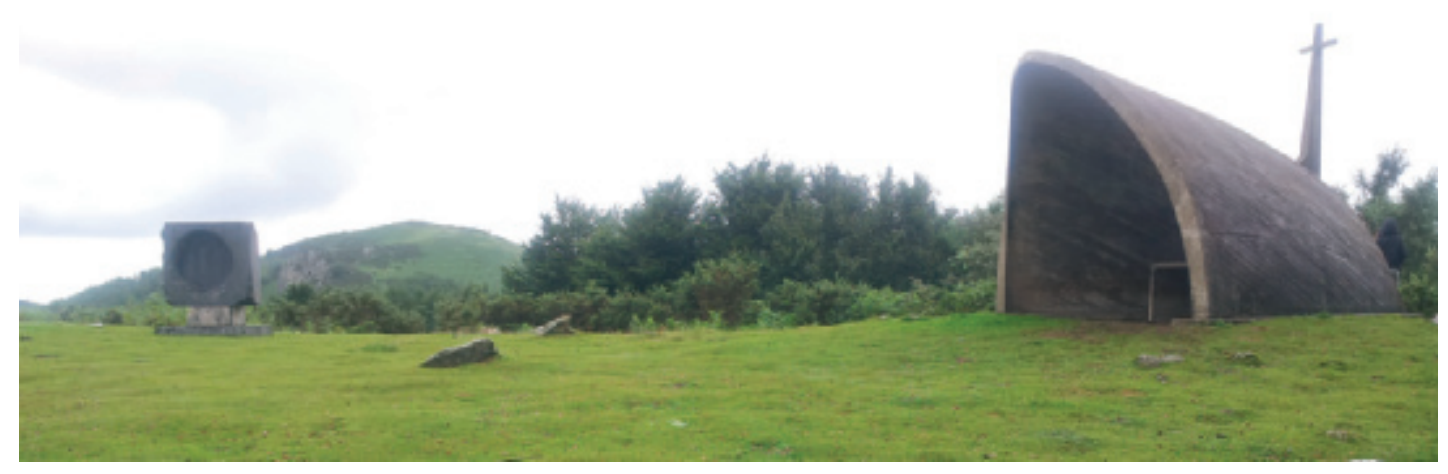

Fig. 6: Homenaje al Padre Donosti, 1958. Piedra, $164 \times 58 \times 155 \mathrm{~cm}$. Lesaka, alto de Aguiña. Fuente: Archivo Emilio Varela Froján.

habrán vivido momentos muy semejantes- era la de un viaje de evasión desde mi pequeña nada a la gran nada del cielo en la que penetraba, para escaparme, con deseo de salvación ${ }^{63}$.

\section{Episodio 2. La cantera.}

Otro de los frecuentes paseos con mi abuelo, era al alto de Orio, en el camino de Zarauz. Había un bosque de hayas junto a una cantera, pequeña y sin explotar de piedra arenisca. Yo jugaba a golpear pedazos de la piedra arenisca con otra distinta y más dura [...] Pues bien, la satisfacción inolvidable, que se me despertó en la cantera, fue perforar la piedra: descubrir el otro extremo libre del agujero. Mi actividad no consistió en otra cosa que hacer agujeros en todas las piedras que podía ${ }^{64}$.

\section{La reflexión de los episodios (SLE) en Oteiza}

Oteiza reflexiona sobre los episodios que ha vivido: "Es ahora que puedo asociar y explicarme estos dos recuerdos. Relacionar mi contemplación del cielo lejano desde el fondo de mi agujero en la arena de la playa, con la fabricación del pequeño vacío, espiritualmente respirable y liberador, del agujero, al alcance de mi mano, en la piedra" ${ }^{65}$.

Todos mis recuerdos positivos de niño [...] he comprendido que eran de naturaleza estética: el cielo redondo y vacío desde el fondo de mi agujero en la arena, el agujero perforado en la piedra [...] la respiración de la ría, se iba y sabía que puntualmente regresaría y yo esperaba con verdadera ilusión, era la ría como una madre para mí. [...] Y todo esto que luego he reconocido en conceptos como respiración espacial, el par dialéctico Ocupación-desocupación espacial, la ley de los cambios, el vacío como obtención estética, como Nada y como Todo ${ }^{66}$.

Pero después de la reflexión son las artes las que dan formas a estas experiencias. Es a través de ellas, de las obras, como el artista puede fijar sus sentimientos ante la naturaleza, lo que pudo ver en ella, en el mundo exterior como realidades visuales y espaciales. Así, el artista deja de

\footnotetext{
63 Oteiza, 1983: 75.

64 Oteiza, 1983: 76.

65 Oteiza, 1983: 76.

66 Pelay Orozco, 1978: 36.
} 
imponer su propia imaginación sobre la naturaleza, es decir, deja de interpretarla. Deja de intervenir de la forma subjetiva y abstracta como lo hacía antes, para acceder de una manera directa a su mismo ser y, con ello, a todos sus secretos. Porque entiende el arte como una experiencia emocional, vinculada a la naturaleza que, como un organismo vivo y protector, le proporciona toda clase de materias sensibles, que el artista incorpora a su trabajo y, al mismo tiempo, a su conciencia ${ }^{67}$.

Cuenta el escritor Félix Maraña ${ }^{68}$ que cuando Oteiza eligió el lugar donde colocar la estela en homenaje al músico y folklorista José Antonio Zulaika (Padre Donostia) en el monte de Aguiña (fig. 6) había estado hablando con la tierra, consultando su parecer y tomando decisiones tras el diálogo. Al ser preguntado sobre su emplazamiento concreto y definitivo por algún periodista, Oteiza declaró que no estaba decidido, pues para ello antes había de consultar a la tierra, solicitando a la misma tierra permiso para intervenir en ella ${ }^{69}$.

\section{La relación de Jorge Oteiza con elementos del medio natural}

Son innumerables las veces que aparece la naturaleza en la obra poética de Oteiza. Cualquiera de sus poemas contiene referencias a ella, que en la mayoría de ocasiones, son las claves de los mismos. Oteiza, para dar forma a sus sentimientos, para describir su estado anímico, se fija continuamente en la naturaleza. En la relación con lo natural se establecen vínculos afectivos, muchos de naturaleza espiritual, que Oteiza dice buscar para encontrar lo que le falta: "Lo que tengo es Naturaleza, lo que me falta no es Naturaleza"70. El artista decía que eran muy habituales en su manera de trabajar las miradas a la naturaleza, y las llamó alguna vez, "Consultas a la Naturaleza"71.

\section{El árbol}

El artista buscará en la naturaleza de un árbol la fuerza y el consuelo necesarios para soportar el dolor por la muerte de su esposa. Es en el árbol, como presencia y cuerpo, donde Oteiza, a falta de su mujer, vierte todo su sentir. Árbol y poeta, juntos, recuerdan con impotencia a Itziar, su mujer ya fallecida, en un fragmento del poema "ITZIAR elegía"72.

“ahora lloro me apoyo en el árbol tenemos único árbol un hermoso fresno que al acostarnos y en la mañana se asoma en la ventana a nuestro cuarto

ha visto morir a Itziar no ha podido hacer nada me acerco lloro junto al árbol miramos los dos al cielo"

Oteiza, una vez más, se acerca a la naturaleza, a lo que hay en ella, no con la intención de poseerla y dominarla. Menos, con la idea de adueñarse de su ser, sino, por el contrario, de com-

${ }^{67}$ Oteiza, 2007a. Consistir estético y raíz metafísica.

${ }^{68}$ Félix Maraña, 1999: 50-51, 113.

${ }^{69}$ Es a esa consulta con la tierra a la que alude el poeta Gabriel Aresti (1984: 327): “Jorge de Oteiza/habló/con la tierra; yo no creo semejante cosa/pero sin embargo/sélque es verdad".

70 Oteiza, 1983: 150.

71 Emilio Varela recuerda en su trabajo con Oteiza: "Cada vez que en nuestro trabajo se planteaba un problema de diseño, Oteiza nos decía que debíamos 'consultar a la naturaleza', porque en ella íbamos a encontrar las respuestas plásticas y las justificaciones estéticas necesarias a nuestros planteamientos”. Conversación con Emilio Varela (27.12.16).

72 Oteiza, 1992: 10. 


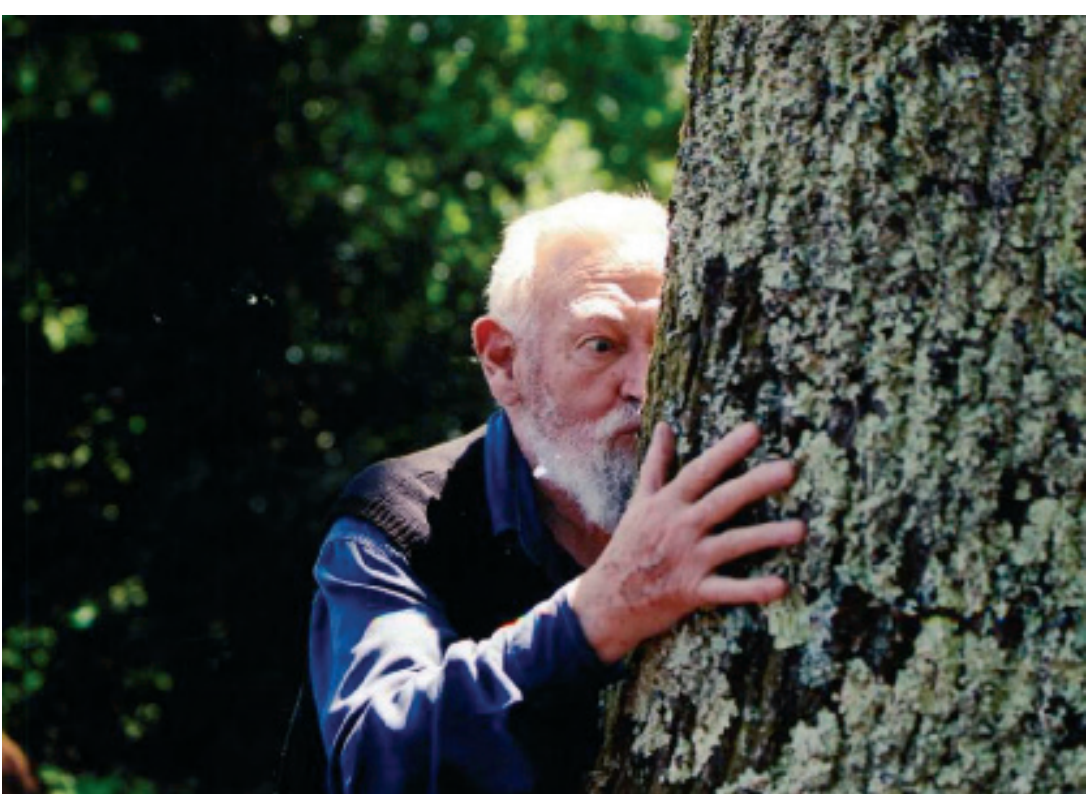

Fig. 7: Oteiza abraza y besa al árbol. Fuente: Archivo Ana María Marín.

partirlo y reconocerse en él, para entender sus mensajes y acercarse a sus secretos, como única forma de poder identificar lo que hay de humanidad en ella. Porque también en el árbol Oteiza se reconoce y se siente a sí mismo. Comprende que es en su presencia donde toma conciencia de su propio existir y que al compartir con él su dolor alivia también su pena (fig. 7). Esta hermandad real entre ambos, entre todos, es expresada por el artista en esta hermosa imagen "las manos levantadas y unidas de los árboles" "73, o en este pensamiento "no sabéis?/un árbol muerto es un hombre muerto"74, que no son otra cosa que la identificación total con su ser y la expresión formal de su sentir. En el mismo sentido, dirá del árbol, con lo que termina definitivamente de humanizarlo ${ }^{75}$ :

"porque también el árbol tiene su cuerpo y su alma

y su cuerpo se prolonga en nuestros cuerpos

y su alma en nuestras almas"

\section{Los animales}

El vínculo naturaleza-persona se establece también con los animales. Oteiza trató de desarrollar en profundidad esta relación ya en uno de sus primeros y más originales libros, "Interpretación estética de la estatuaria megalítica americana"76, donde, elaboró y representó el mito del hombre-jaguar ${ }^{77}$ de las altas culturas andinas.

73 Oteiza, 1990b: 182.

74 Oteiza, 1990b: 24.

75 Oteiza, 1990b: 21.

76 Oteiza, 2007.

77 En el prólogo "Arte, ciencia y mito" a la edición crítica de "Interpretación estética de la estatuaria megalítica americana" (Oteiza, 2007: 59-60), María Teresa Muñoz comenta al respecto del concepto de máscara: "Ésta es una de las aportaciones más originales de la interpretación estética que propone Jorge Oteiza, el concepto de máscara como fusión de los caracteres propios del hombre y el jaguar, como alianza entre la naturaleza humana y la naturaleza animal, para colocarse por encima de la condición temporal y el rostro móvil del universo". 
Lo que para Oteiza suponía el entendimiento global de lo artístico, y no sólo del particular arte de aquella cultura, sino, también -y era lo importante de su investigación-, dar con un comportamiento genérico del artista, en todo tiempo y lugar, frente a la vida y la naturaleza. Además pretendía dar con las claves para la materialización de las ideas generales sobre el hecho estético que, lo mismo, sirvieron a aquellos escultores, que le sirven hoy a cualquier artista. Estas claves permitieron al escultor identificarse con sus esculturas, a las que consideró como modelos de síntesis plástica y ejemplos de integración con lo natural. Porque de lo que trata Oteiza en este libro es, en definitiva, de la íntima relación que guardan la naturaleza y las artes. El artista plantea aquí la doble dimensión estética que organiza los elementos y los rostros naturales, el animal y el humano, en las interpretaciones del Paisaje ${ }^{78}$ y en las representaciones de la Máscara.

Es, de esta forma, a través de un proceso lento de profunda humanización de todo lo natural -que consiste en el reconocimiento íntimo de formar parte del mundo y en la integración sensible con lo que le rodea- que el artista toma conciencia de la realidad y de la naturaleza, de la existencia y de la vida. Y lo representa y expresa en los mitos y ritos, por mediación de los animales y de los elementos naturales -reales y míticos-, que humaniza en los paisajes y las máscaras. Pues todo lo humano, estéticamente, sucede entre el animal y la máscara, entre los elementos naturales y el paisaje. Oteiza decía de sí mismo al comienzo de su libro de poemas "Existe Dios al Noroeste"79: "animal fronterizo me declaro en Irún/y consecuente y fronterizo he sido/entre animal y hombre/entre la ciudad y la montaña/entre la montaña y la carretera/entre los demás y la montaña".

Así, son constantes las apariciones de animales también en su poesía. Aparecen el pájaro, el pez, el perro, el caballo, la vaca -"campanario de vacas la tarde" 80 , la lagartija, el ciervo, la rata, el gusano, el murciélago - del que dice "caído condenado a pájaro ciego/implume equivocado/y con vuelo de trapo"81-, el cangrejo, el carnero, el elefante, el buitre, el bisonte, el búfalo, el búho, el pingüino, el tigre... con los que habla y a los que escucha decir sus mensajes, con los que comparte su condición y a los que consulta y pregunta. Por ejemplo, identifica la condición existencial del hombre con la limitación al vuelo del avestruz, de esta forma: "decía [...] del avestruz-hombre/maravilloso y calumniado animal/tiene alas y no puede volar/como el hombre" 82 . También son materia de su poesía los insectos como moscas, grillos, cigarras, mariposas, abejas, hormigas... que humaniza y personifica para decir cosas como "aplauden blancas mariposas" 83 o "serruchos de cigarras le cantan" 84 , que le devuelven a su infancia -otra vez su infancia.

\section{El agua}

Oteiza observa en el mundo reflejos de su interior, que continuamente encuentra en la naturaleza, en lo que ella contiene, con los que se identifica plenamente, pues forman parte de su ser y de su conciencia, que está movida por la intuición y los afectos. Por ejemplo, un elemento natural con el que identifica directamente su sentir es el agua, con la que establece unos vínculos afectivos al reconocer en ella el fluir constante de sus pasiones y de sus emociones más íntimas. Sus poemas, a veces, las reflejan en forma de lluvia y lágrima, de nieve, nube y niebla, de gota y diluvio; y otras veces, en forma de mar, de ola y espuma, de río y pozo, de fuente. A veces describe estados de profunda tristeza, de gran melancolía, a través del agua ${ }^{85}$.

78 "El Paisaje es como un cuerpo múltiple y sensible, cargado de misteriosas energías y que rueda fatalmente sobre nosotros con la clave de nuestro propio destino. A formas distintas de hombre corresponden distintas interpretaciones del paisaje. Nuevas formas culturales son nuevas formas del paisaje, diferentes concepciones del mundo, diferentes estilos de arte, distintos recursos y formas de salvación" (Oteiza, 2007: 101).

79 Oteiza, 1990b: 8.

80 Oteiza, 1990b: 59.

81 Oteiza, 1990b: 174.

82 Oteiza, 2006: 643.

83 Oteiza, 1990b: 187.

${ }^{84}$ Oteiza, 1990b: 188.

85 Oteiza, 1990b: 78-79. 

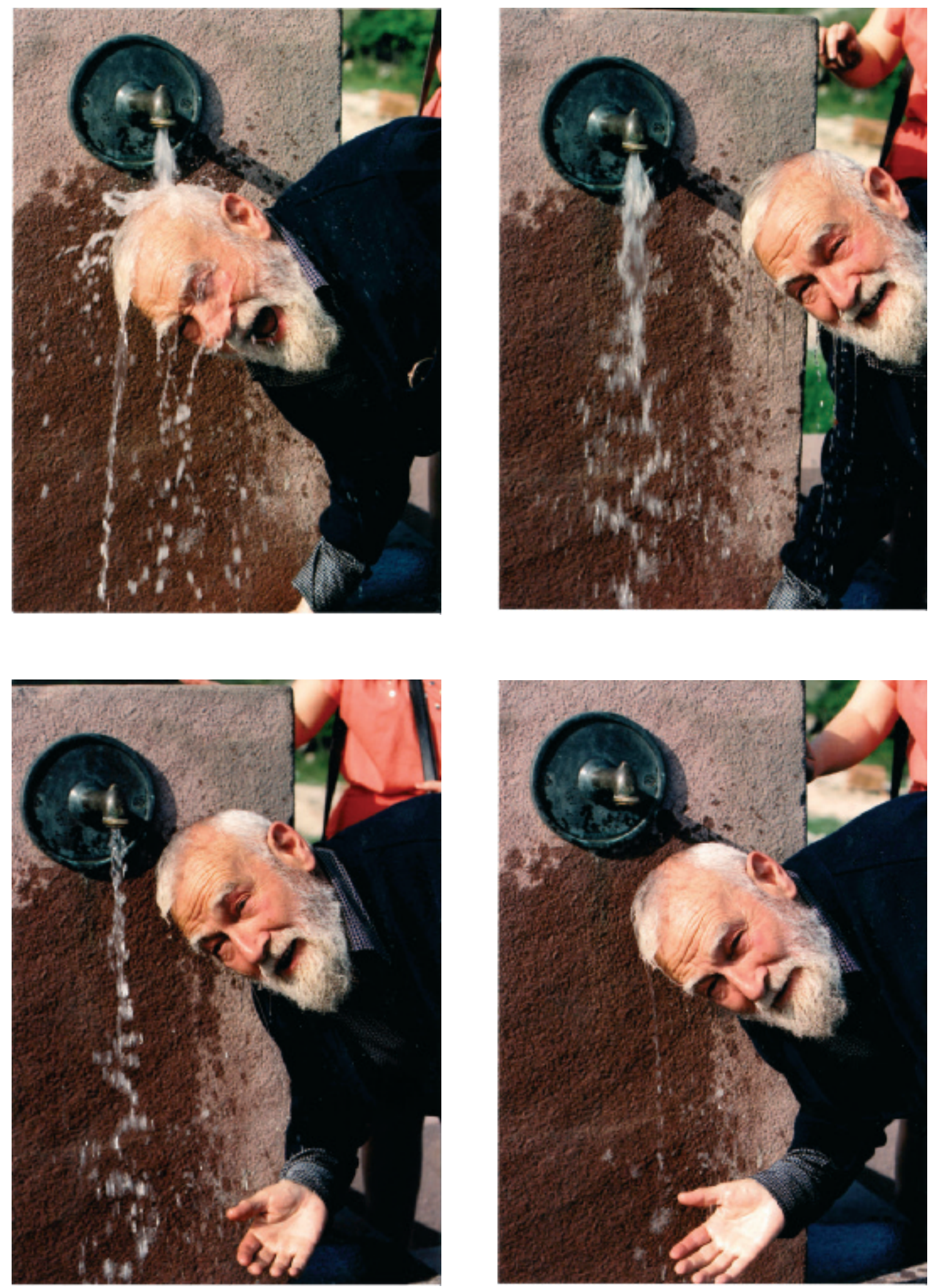

Fig. 8-9-10-11: Oteiza juega con el agua que le devuelve la alegría. Fuente: Archivo Ana María Marín. 
"me salpica el agua en la orilla pongo mi cara al cielo quiero que sea la lluvia que me acaricie con sus manos quiero morir de shirimiri"

Es a partir de las propiedades poéticas y estéticas del agua que el artista piensa en su propia naturaleza y es capaz de compartir con ella su sentir. En ella se sumerge y nada -"aquel lleno de agua que nadaba ya llegaba"86 -, como cuando en la fuente de Alzuza mojaba su cabeza y se llenaba de agua (figs. 8, 9, 10 y 11), sintiendo la vida como cuando sentía de niño en Orio la respiración de su ría, que recordaba, viva y protectora, de la siguiente forma ${ }^{87}$ : “Ah, y la ría de Orio, adoro la ría de Orio, era como si fuera mi madre, solía esperar con ilusión a que subiera, y cuando bajaba, cuando se iba, me producía tristeza".

La relación de Oteiza con elementos como el agua, con la que establece unas relaciones especiales, y que emplea como material poético, llega incluso a aspectos no solo emocionales, sino espirituales y telúricos, como es el caso del poema "Nieblas en el Izarraitz" "88, donde a partir de la niebla quedan de alguna manera reflejados finalmente cada uno de sus vínculos con el resto del mundo y de la naturaleza.

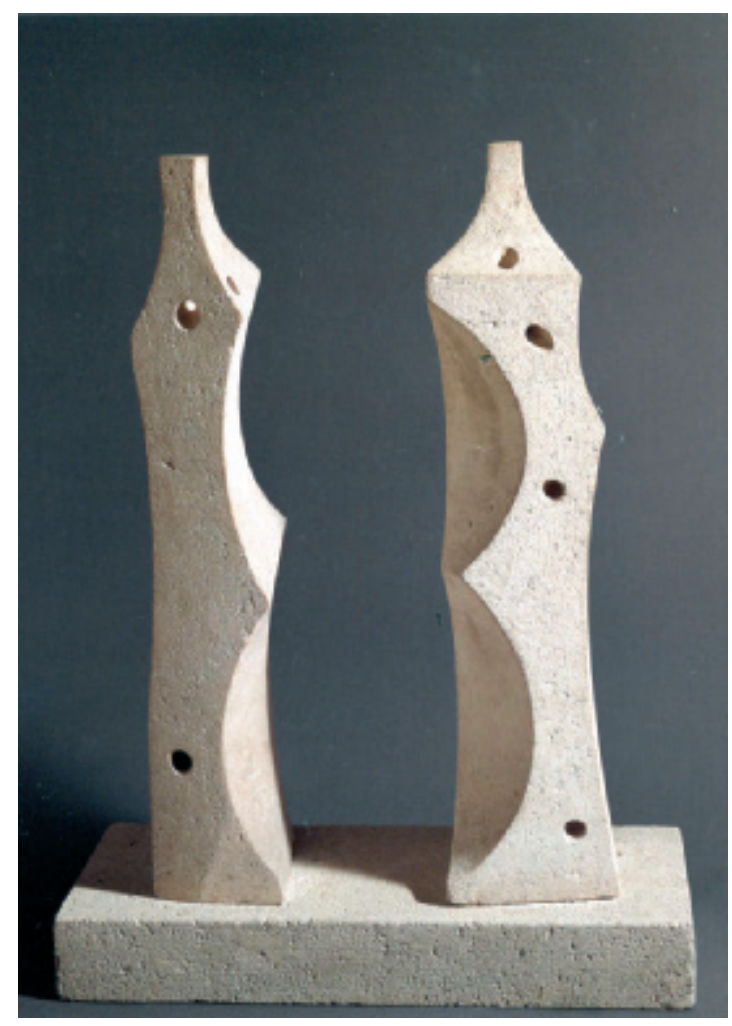

Fig. 12: La tierra y la luna, 1955. Piedra caliza, $80 \times 59 \times 25 \mathrm{~cm}$. Colección privada, Madrid. Fuente: Badiola, 2004: 131.

\section{Los paisajes y otros elementos del medio natural}

En sus poemas aparecen además lugares como ríos, montañas, bosques, desiertos, playas, mares, cielos, horizontes, abismos, agujeros... ${ }^{89}$, con los que se identifica profundamente. Son espacios donde el artista ve reflejada su intimidad (fig. 12). O, finalmente, elementos de la naturaleza como las piedras, el aire, el agua, el fuego... a través de los cuales expresa sus deseos y protestas. Todo conservando el misterio y el espíritu de la naturaleza que de forma natural va haciéndose visible en su poesía. Así se lo decía en una entrevista a José Luis Merino ${ }^{90}$ :

Todo es un misterio maravilloso, podía decirse; pero no hay tal misterio, sino una realidad visual, espiritual. Si no se sabe eso, no se sabe qué es una playa, una ola, un árbol, ... no se sabe qué es la meada de un perro cuando levanta la pata tan a gusto y suelta la meada. Todo lo que se ve es sagrado. Y lo que no se ve es una sacralidad oculta, una deficiencia nuestra visual. Ver lo que no existe, eso es lo que hace el artista. Ver lo que no existe.

\footnotetext{
86 Oteiza, 1992: 34.

87 Pelay Orozco, 1978: 63.

88 Oteiza, 1990b: 97.

89 Oteiza, 1990b.

${ }^{90}$ Merino, 2008: 40.
} 
Esta filosofía visual hace al artista tener una actitud contemplativa ante la naturaleza que le obliga a una reacción activa de su intimidad personal o, lo que es igual, a reconocer en ella lo que siente en su interior. Es decir, busca el reconocimiento estético y poético de sus contenidos, que en él toman forma plástica en sus esculturas y en sus poemas. Son sentimientos de una profunda empatía con lo natural, como cuando contemplando la naturaleza dice "sentir la tristeza de un paisaje".

Oteiza es capaz, no sólo de intuir los significados que los paisajes encierran, sino de visualizar el silencio de sus límites como inmovilidad y vacío. Porque su relación con la naturaleza no se queda sólo en lo metafórico y simbólico, sino que el artista consigue dar forma precisa a todo lo metafísico. De acuerdo que el paisaje sí es la máscara en el rostro de la naturaleza, pero la forma de lo natural, que tiene su propia luz, no es sólo la visión de su imagen, sino también lo es de su inmovilidad. Esto es: no siempre se obtiene de ella unos significados; a veces, la naturaleza resiste en sus silencios o, de otra forma, en sus absolutos.

En definitiva, la naturaleza es para Oteiza fuente no sólo de los recursos materiales, sino de los inmateriales, que son realmente los que interesan a su conciencia, y que aparecen en sus obras. Materiales de naturaleza sensible con los que expresa su sentir y, a través de los cuales, puede conocer mejor, en un proceso continuo de integración, su propia realidad y el mundo que le rodea. Una realidad, la suya, que incorpora al mismo tiempo naturaleza, arte y espiritualidad, en una síntesis final de los elementos naturales con su conciencia.

\section{Conclusiones}

La naturaleza nos ofrece siempre su capacidad para hablarnos. Para conformar un adecuado vínculo persona-naturaleza se hace necesario aprender a escuchar sus mensajes y sus silencios. Para ello es conveniente aprender a mirar profundamente, con mirada escrutadora, indagadora, sin que la prisa nos condicione. Se trata de potenciar la educación de la mirada para conseguir contemplar, con la profundidad que requiere, la naturaleza y sus múltiples lenguajes, entre ellos el estético.

En la relación entre las personas y la naturaleza se interpretan mensajes basados tanto en lo físico y tangible como en lo metafísico, trascendente o espiritual. La estética, como forma de interacción humana con la realidad, puede ayudar en el descubrimiento e interpretación de estos mensajes, buscando la esencia de lo que las cosas en realidad son y los mensajes que nos pueden dar, tanto los más evidentes como los más escondidos.

La relación que muchos artistas establecen con lo natural a través de las SLE determinan su concepción del hecho estético. En el caso de Oteiza se produce un ejemplo de comprensión del mundo a través de la síntesis del trinomio 'naturaleza-arte-espiritualidad'. El arte de Oteiza pone en valor estas dimensiones y las reconoce como los espacios íntimos e interiores de conciencia, en los que trabaja unas estéticas de la inmovilidad y unas poéticas de la ausencia y del silencio. Para ello utiliza las formas metafísicas de los límites y de los vacíos. Oteiza se configura así como modelo a seguir en la educación de la mirada escrutadora y sintética, en la que encuentra la comprensión de lo natural, incluida su parte metafísica.

\section{BIBLIOGRAFÍA}

Abram, D. (1996): The spell of the sensuous: Perception and language in a more-than-human world. Nueva York: Vintage Books.

Abram, D. (2010). Becoming animal: An earthly cosmology. Nueva York: Pantheon Books.

Aresti, G. (1984). Maldan behera/Harri eta herri. Pendiente abajo/Piedra y pueblo. Madrid: Ediciones Cátedra, S. A.

Badiola, T. (1988): Propósito Experimental. Madrid: Fundación Caja de Pensiones.

Badiola, T. (2004): OTEIZA, mito y modernidad. Bilbao: FMGB Museo Guggenheim Bilbao.

Bai, H. (2015). "Peace with the earth: Animism and contemplative ways". En: Cultural Studies of Science Education, 10, 1, pp. 135-147. 
Barnhardt, R. y Kawagley, O. (2010): Alaska Native education: Views from within. Fairbanks. AK: University of Alaska Press.

Berry, T. (1988): The dream of the earth. San Francisco: Sierra Club Books.

Castro, J. M. (2012): Aproximación a la inteligencia espiritual. Gran Canaria: ISTIC Instituto Superior de Teología de las Islas Canarias-Sede Gran Canaria.

Chawla, L. (1998): "Significant Life Experiences Revisited: a review of research on sources of environmental sensitivity". En: Environmental Education Research, 4, 4, pp. 369-382. doi.org/10.1080/1350462980040402.

Chawla, L. (1999): "Life paths into effective environmental action". En: The Journal of Environmental Education, 31, 1, pp. $15-26$.

Chawla, L. (2001): "Significant Life Experiences Revisited Once Again: response to Vol. 5 (4). Five Critical Commentaries on Significant Life Experience Research in Environmental Education". En: Environmental Education Research, 7, 4, pp. 451-461. doi: 10.1080/13504620120081313.

Clayton, S. y Myers, G. (2015): Conservation Psychology. Understanding and promoting human care for nature. Oxford: Wiley Blackwell.

Declaration of the United Nations Conference on the Human Environment (1972). En: http://www.unep.org/Documents. Multilingual/Default.asp?DocumentID=97\&ArticleID=1503\&l=en [consulta: 20-09-15].

Flowers, M., Lipsett, L., and M.J. Barrett. (2014): “Animism, Creativity, and a Tree: Shifting into Nature Connection through Attention to Subtle Energies and Contemplative Art Practice”. En: Canadian Journal of Environmental Education, 19, pp. 111-126.

Francisco I (2015): Carta Encíclica Laudato si’ sobre el cuidado de la casa común. Santa Sede. Disponible en: http:// w2.vatican.va/content/francesco/es/encyclicals/documents/papa-francesco_20150524_enciclica-laudato-si.pdf [consulta: 05-09-15].

Gardner, H. (2010): La inteligencia reformulada. Las inteligencias múltiples en el siglo XXI. Madrid: Paidós.

Gómez Aguilera, F. (1994): “Arte y naturaleza en la propuesta estética de César Manrique”. En: Atlántica: Revista de arte $y$ pensamiento, 8 , pp. 58-63.

Hawks, S. R. (1994): "Spiritual Health: Definition and Theory". En: Wellness Perspectives, 10, 4, pp. 3-11.

Hedlund-de Witt, A. (2013): "Pathways to Environmental Responsability: A Qualitative Exploration of the Spiritual Dimension of Nature Experience". En: Journal for the Study of Religion, Nature and Culture, 72, 2, pp. 154-186.

Keniger, L.E., K. J. Gaston, K. N. Irvine, and R. A. Fuller. (2013): “What are the benefits of interacting with nature?”. En: International Journal of Environmental Research and Public Health, 10, pp. 913-935. doi:10.3390/ijerph10030913.

Kollmuss, A., and J. Agyeman. (2002): "Mind the Gap: Why do people act environmentally and what are the barriers to pro-environmental behavior?". En: Environmental Education Research, 8, 3, pp. 239-260. doi.org/10.1080/ 13504620220145401.

Leopold, A. (1966): A sand county almanac. New York: Oxfor University Press.

Mallarach, J. M. ' (2008): Valores Culturales y Espirituales de los Paisajes Protegidos. (Volumen 2 de la serie Valores de los Paisajes Terrestres y Marinos Protegidos), Sant Joan les Fonts: UICN, GTZ y Obra Social de Caixa Catalunya.

Manrique, C. (2005): César Manrique la palabra encendida. Selección de textos e introducción de Fernando Gómez Aguilera. León: Universidad de León.

Maraña, F. (1999): Jorge Oteiza, elogio del descontento. San Sebastián: Editorial Bermingham.

Merino, J. L. (2008): Habla Oteiza. Bilbao: Editorial Avance Proyectos. Colegio Oficial de Arquitectos Vasco-Navarro.

Oteiza, J. (1983): Quousque tandem...! Ensayo de interpretación estética del alma vasca. San Sebastián: Editorial Hórdago. 4. ${ }^{\mathrm{a}}$ edición.

Oteiza, J. (1988): Cartas al principe. Zarautz: Editorial Itxaropena.

Oteiza, J. (1990a): Ley de los cambios. Zarautz: Ediciones Tristan-Deche Arte Contemporáneo.

Oteiza, J. (1990b): Existe Dios al noroeste. Pamplona: Editorial Pamiela. 3. a edición: Noviembre, 1990.

Oteiza, J. (1992): “Itziar” elegía y otros poemas. Pamplona: Editorial Pamiela. 2. a edición: octubre 1992.

Oteiza, J. (1995): Estética del huevo. Huevo y Laberinto. Mentalidad Vasca y Laberinto. Pamplona: Editorial Pamiela.

Oteiza, J. (1997): Goya mañana. El Realismo inmóvil. El Greco, Goya, Picasso. Alzuza-Nafarroa: Fundación-Museo Jorge Oteiza.

Oteiza, J. (2006): Poesía. Navarra: Edición crítica de la obra de Jorge Oteiza. Alzuza-Nafarroa: Fundación Museo Oteiza.

Oteiza, J. (2007a): Propósito experimental 1956-1957. Reedición facsímil del original Escultura de Oteiza. Catálogo. IV Bienal de São Paulo, 1957. Navarra: Fundación Museo Oteiza. Primera reimpresión: Diciembre 2014.

Oteiza, J. (2007b): Interpretación estética de la estatuaria megalítica amaricana. Carta a los artistas de América. Sobre el arte nuevo en la postguerra. Navarra: Edición crítica de la obra de Jorge Oteiza de la Fundación Museo Oteiza.

Palmer, J. (1998): Environmental education in the 21st century: Theory, practice, progress and promise. Londres: Routledge.

Pelay Orozco, M. (1978): “Oteiza” su vida, su obra, su pensamiento, su palabra. Bilbao: Editorial La Gran Enciclopedia Vasca.

Plumwood, V. (2002): Environmental culture: The ecological crisis of reason. Nueva York: Routledge.

Russel, K. C. (2012): "Therapeutic Uses of Nature”. En: Clayton, S. (ed.). (2015): The Oxford handbook of environmental and conservation psychology. Nueva York: Oxford University Press, pp 428-444. 
Seton, E.T. (1941): Trail of an Artist-Naturalist. The autobiography of Ernest Thompson Seton. Nueva York: Charles Scribner's sons.

Tanner, T. (1980): "Significant life experiences: a new research area in environmental education". En: Journal of Environmental Education, 11, 4, pp. 20-24.

Thoreau, H. D. (2004): Walden. Princeton: Princeton University Press.

Torralba, F. (2011): Inteligencia espiritual. Barcelona: Plataforma editorial.

Tsevreni, I. (2011): “Towards an environmental education without scientific knowledge: an attempt to create an action model based on children's experiences, emotions and perceptions about their environment". En: Environmental Education Research, 17, 1, pp. 53-67. doi:10.1080/13504621003637029.

Vining, J., y M. S. Merrick. (2012): "Environmental Epiphanies: Theoretical Foundations and Practical Applications". En: Clayton, S. (ed.). (2015): The Oxford handbook of environmental and conservation psychology. Nueva York: Oxford University Press, pp 485-508.

Whitman, W. (1981): Hojas de hierba. Barcelona: Mayol Pujol.

Williams, K.; D. Harvey. 2001: “Transcendent experience in forest environments”. En: Journal of Environmental Psychology, 21, pp. 249-260.

Wolman, R. (2001): Thinking with your soul. Spiritual intelligence and why it matters. Nueva York: Harmony books.

Fecha de recepción: 11-V-2016

Fecha de aceptación: 7-XI-2016 